\title{
Dual occipital and supraorbital nerve stimulation for chronic migraine: a single-center experience, review of literature, and surgical considerations
}

\author{
Shannon Hann, M.D., and Ashwini Sharan, M.D. \\ Department of Neurosurgery, Thomas Jefferson University, Philadelphia, Pennsylvania
}

\begin{abstract}
Occipital nerve stimulation (ONS) has been studied in a few clinical trials for the treatment of chronic migraine (CM) with failure to prove sufficient efficacy. To date, peripheral nerve stimulation for the treatment of primary headache is limited to off-label use only. The authors report their institutional experience in CM therapy with combined ONS and supraorbital nerve stimulation (SONS). Fourteen patients treated with dual ONS and SONS for CM were studied with follow-up ranging from 3 to 60 months. Seventy-one percent achieved successful stimulation as defined by a $50 \%$ or greater decrease in pain severity. The mean reduction in headache-related visual analog scale (VAS) score was $3.92 \pm 2.4$. Half of the patients also had resolution of migraine-associated neurological symptoms and returned to normal functional capacity. The main adverse events included lead migration (42.8\%), supraorbital lead allodynia $(21.4 \%)$, and infection $(14.2 \%)$ with a resulting high reoperation rate $(35.7 \%)$. The authors' stimulation efficacy was superior to the combined $33 \%$ positive response rates ( $\geq 50 \%$ pain reduction) in the published studies of ONS for CM. This is likely due to the fact that topographical paresthesia induced by combined ONS and SONS covers the area of migraine pain better than ONS alone. The authors also discuss effective surgical techniques to prevent patient morbidity.
\end{abstract}

(http://thejns.org/doi/abs/10.3171/2013.6.FOCUS13233)

KEY WORDS • occipital nerve stimulation $\quad \bullet \quad$ supraorbital nerve stimulation
chronic migraine

$\mathrm{C}$ HRONIC migraine is a prevalent and debilitating primary headache disorder with an annual incidence rate of 3\%.2,20 The disorder is defined as having more than 15 headache days per month of which at least 8 days meet the criteria for migraine without aura. ${ }^{6} \mathrm{Com}-$ pared with the episodic form of migraine, individuals with CM suffer greater disability, more economic burden, and worse health-related quality of life. ${ }^{13}$ Furthermore, CM is associated with higher rates of major depression and suicide attempts than those found in the general population. ${ }^{3}$

Although the pathophysiology of migraine is unclear and complex with involvement of multiple levels of pain circuitry in the CNS, the mainstay of treatment is rather orthodox. It starts with establishing a correct diagnosis and trial of preventative and abortive medication therapy by the headache neurologist. For individuals with medically refractory migraine, Botox injections, selective nerve blocks, surgical decompression, and neurectomy procedures have been described with varying success. ${ }^{12,24}$

\footnotetext{
Abbreviations used in this paper: $\mathrm{CM}=$ chronic migraine; $\mathrm{ONS}=$ occipital nerve stimulation; SONS = supraorbital nerve stimulation; VAS = visual analog scale.
}

Weiner and Reed first published their experience of implanting a subcutaneous electrode in 17 patients with occipital neuralgia and achieved 12 sustained positive results ( $>50 \%$ pain control). ${ }^{23}$ Since then the efficacy of ONS for intractable occipital neuralgia has been well established with $88 \%$ of patients overall reporting a positive response. Popeney and Aló first reported their experience of treating transformed migraines (primary headache with migrainous features focused over the occipitocervical region) with neuromodulation and achieved 50\% or greater reduction in headache frequency in $88 \%$ of patients. ${ }^{14}$ This signified a paradigm shift from treating a particular anatomical distribution of pain to treating a class of headache syndromes with peripheral nerve stimulation. ${ }^{15}$ In the following decade, the investigation of treating primary headache with neuromodulation was carried out mainly with ONS. ${ }^{4,17,19}$

To date, 3 prospective, randomized, blinded trials have been published detailing the safety and efficacy of ONS in treating CM. The first published prospective, controlled trial, the Occipital Nerve Stimulation for the Treatment of Intractable Migraine (ONSTIM) study in 2011, showed that $39 \%$ of 29 patients in the adjustable stimula- 
tion group, $6 \%$ of the 16 patients in the preset stimulation group, and none of the patients in the medically managed group responded to treatment at 3 months of follow-up. ${ }^{17}$ Responders were defined as having a $50 \%$ reduction in the number of headache days per month, or a 3-point or greater reduction in pain intensity. In the Precision Implantable Stimulator for Migraine (PRISM) study, a multicenter, double-blinded, randomized controlled study carried out from 2009 to 2012, there was not a significant difference in the reduction of migraine days between the 63 active-stimulation patients and a 62 sham-stimulation patients (decrease of 5.5 vs 3.9 migraine days/month). ${ }^{20}$ Most recently, Silberstein et al. conducted a larger-scale (150 patients) multicenter double-blind, randomized controlled trial with an end point of difference in the percentage of responders between the active and control group as defined by $50 \%$ or greater reduction in the mean daily VAS score at 12 weeks. ${ }^{20}$ However, although there was a significant difference in achieving $30 \%$ pain reduction and a reduction in the number of headache days and migraine-related disability between the groups, this study also failed to meet its primary end point, with only $17.1 \%$ in the active-stimulation group and $13.5 \%$ in the shamstimulation group having $50 \%$ or greater reduction of pain. Based on these unfavorable results, peripheral nerve stimulators are yet to be approved by the US FDA for the treatment of medically refractory migraine.

In the latter half of the past decade, other new trends in utilizing peripheral nerve stimulation for cephalgia emerged, including the application of SONS to treat cluster headaches and combined ONS and SONS for treatment of various trigeminal neuralgias and facial pain syndromes. ${ }^{1,8,21}$ We report our institutional experience with 14 cases of CM that were treated with ONS and SONS in the hope of adding evidence to the growing knowledge of neuromodulation for primary headache treatment as well as adding neurosurgical perspective in techniques to prevent lead-related complications.

\section{Methods}

\section{Patient Selection}

A review of 14 consecutive patients with $\mathrm{CM}$ who underwent combined ONS and SONS between 2008 and 2013 was carried out after obtaining approval from our institutional review board. Patients were all referred by experienced headache neurologists from our institution after meeting the International Classification of Headache Disorders: 2nd Edition (ICHD-2) diagnostic criteria, established by the International Headache Society, as having CM. Polypharmacological therapy had failed in all patients ( 6 medications on average), as had other interventions such as Botox injections and nerve blocks that were offered by the neurologists' office. The patients subsequently underwent an ONS and SONS trial conducted by pain management anesthesiologists at our institution to establish a good response rate of at least $50 \%$ pain reduction during the 5-day trial period. Only patients who underwent this process were referred to the senior author's clinic for placement of permanent stimulators. A neuropsychologist preoperatively established patients to be free of narcotic overuse and psychiatric comorbidities.

\section{Surgical Implantation}

After intubation and general anesthesia, the patient was positioned with the head in a horseshoe-shaped head holder, and a gel roll was placed under the ipsilateral shoulder in a lateral position. After prepping and draping the ipsilateral forehead, neck, and chest, the incision site and needle insertion site were marked. For SONS, 1 incision was made in the lateral forehead (approximately $1.5 \mathrm{~cm}$ superolateral to the tip of eyebrow) for the Tuohy guide needle (or the percutaneous peel-away introducer sheath insertion site). Another incision was made in the right temporal region, to which the distal SONS wire was tunneled. The Tuohy needle was prebent to the curvature of the forehead. The direction was chosen in such a way that the electrode contacts were positioned perpendicular to the course of the supraorbital nerves. A standard electrode (4-contact or 8-contact) was passed into the epifascial plane, and the tip of the electrode was buried subperiosteally to hold the tip down. After removing the guide needle, the electrode was tunneled back to the incision in the right temporal region, and a titanium dog bone-shaped plate was used to anchor the electrode to the cranium at the temporal incision (Fig. 1). Subsequently, a strain relief loop was created here, and the distal wire was further tunneled down to the neck behind the ear. For ONS implants, a separate incision was placed behind the mastoid process. The electrode was tunneled from an entry point a few centimeters away from the incision to the midline using the appropriately bent Tuohy needle while aiming along the level of the C-1 arch. After the electrode was placed, the lead was then tunneled to the incision behind the mastoid and was anchored with 2 plastic anchors. A strain relief loop was also created and tucked into the subcutaneous fascia. In the end, a battery unit pocket was made in the buttocks, subclavicular region, or abdomen (ipsilaterally) based on the patient's preference. Both leads from SONS and ONS were tunneled down to the pocket, and the battery was inserted. Of note, some surgeons prefer to operate with monitored anesthesia care without intubation so that patients can be woken up during the operation to confirm paresthesia coverage..$^{15}$ Oth-
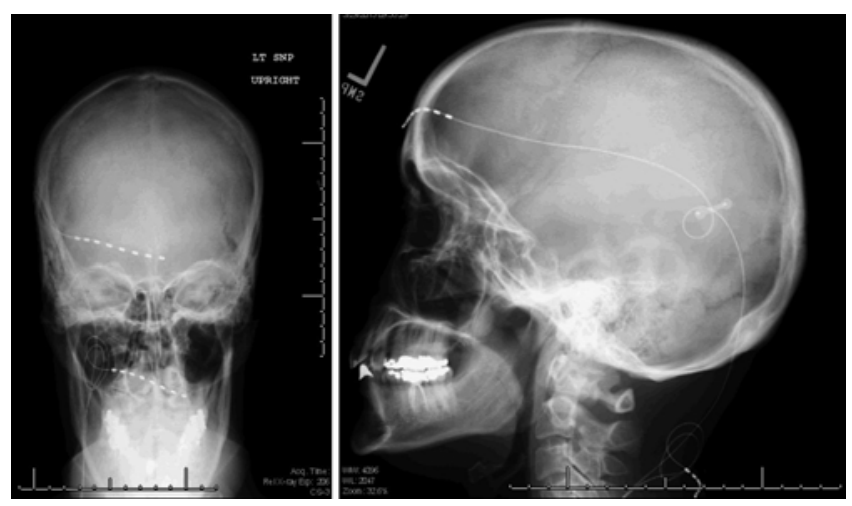

FIG. 1. Postoperative skull radiograph showing bilateral occipital leads and left supraorbital leads anchored with a dog bone-shaped plate (right). 
ers may use intraoperative fluoroscopy to confirm the locations of the leads. ${ }^{22}$

\section{Follow-Up and Data Collection}

For the first few months after implantation, each patient underwent frequent follow-up in the clinic and response evaluation with manufacturer representatives to achieve maximal benefit programming. After this period, the patient returned to the clinic every 3-6 months for the 1st year and yearly thereafter to continue monitoring pain relief. During the follow-up visits, information regarding the percentage of pain reduction, pain-related VAS score, presence of migraine-associated neurological features, functional status, and complications were collected. Statistical analysis for predictive factors of successful stimulation was unable to be carried out because of the insufficient statistical power of study from the small sample size.

\section{Results}

\section{Patient Demographics}

All 14 patients had a well-documented history of CM with or without auras (Table 1). The mean age at placement was $41.5 \pm 10.7$ years old with females accounting for $78.6 \%$ (11 of 14) patients. The mean duration of symptoms was $6.8 \pm 5.1$ years. The mean baseline headacherelated VAS score was 6.3 points, and during acute migraine attack it was 8.6 points. On average, 4 headache medications were used and only 3 patients had prescribed narcotic use. Functional capacities were categorized into limited (lack of optimal concentration required for work/activities), impaired (multiple missed work dates for headache and related treatments), incapacitated (unable to keep a job due to pain), and homebound (unable to carry out daily activities). Six (43\%) of 14 patients were found to be incapacitated or homebound due to daily CM. Of note, 3 of 14 patients (Cases 3, 6, and 7) underwent previous bilateral ONS electrode placement by the senior author for CM treatment and were again referred by the headache neurologists due either to incomplete resolution of headache or a new frontal headache not covered by the occipital nerve stimulators.

\section{Headache Stimulation Response}

The follow-up period ranged from 3 to 60 months (mean 31 months); 9 patients had 2 years or longer followup. The percentage reduction in the severity of headache, resolution of associated neurological symptoms, reduction in VAS score, postoperative functional status, and reduction in narcotic use were collected along with the stimulator profile such as unilateral versus bilateral leads and location of the battery unit (Table 2). Five patients had bilateral and 9 had unilateral electrode placement on the symptomatic site. Ten $(71 \%)$ of the patients had positive response to the therapy as defined by at least $50 \%$ improvement in headache severity. Of these 10 patients, 6 had $90 \%$ or greater pain reduction and were able to resume normal functional status and ceased emergency department visits for headache crisis. Of the 10 patients with associated neurological symptoms, 5 (50\%) had symptom resolution and all 5 were among the patients with a higher percentage of pain reduction. The VAS score at the most recent follow-up was $3.4 \pm 2.3$ points with a mean VAS reduction of $3.92 \pm 2.4$ points. Of note, the 3 patients who had ONS previously and underwent SONS placement

TABLE 1: Demographic information for 14 patients with CM who underwent placement of ONS and SONS devices*

\begin{tabular}{|c|c|c|c|c|c|c|}
\hline $\begin{array}{l}\text { Case } \\
\text { No. }\end{array}$ & $\begin{array}{l}\text { Age at Op } \\
\text { (yrs), Sex }\end{array}$ & $\begin{array}{c}\text { Duration of } \\
\text { CM (yrs) }\end{array}$ & Neurological Symptom & $\begin{array}{l}\text { VAS } \\
\text { Score }\end{array}$ & Headache Medications & $\begin{array}{c}\text { Functional } \\
\text { Status }\end{array}$ \\
\hline 1 & $27, \mathrm{~F}$ & 6 & lacrimation & $6-7$ & droperidol, MS Contin, verapamil & impaired \\
\hline 2 & $45, \mathrm{~F}$ & 4 & dizziness, poor speech & $7-9$ & Topamax, Seroquel, DHE, Effexor & impaired \\
\hline $3 \dagger$ & $30, \mathrm{M}$ & 4 & lack of concentration & 8 & Elavil, Topamax, Seroquel, verapamil & impaired \\
\hline 4 & $46, M$ & 10 & paresthesia in rt arm & $8-10$ & $\begin{array}{l}\text { Topamax, droperidol, Valproate, NSAIDs, Vera- } \\
\text { pamil }\end{array}$ & homebound \\
\hline 5 & $41, \mathrm{~F}$ & 6 & dizziness & 8 & Abilify, NSAIDs, lithium, Vicodin, droperidol & incapacitated \\
\hline $6 \dagger$ & $48, F$ & 20 & none & $5-8$ & Buspon, Abilify, Effexor, NSAIDs & incapacitated \\
\hline $7 \dagger$ & $49, \mathrm{~F}$ & 12 & blurred vision, lacrimation & $6-9$ & $\begin{array}{l}\text { phenelzine, Verapamil, Sumatriptan, Topamax, } \\
\text { NSAIDs }\end{array}$ & incapacitated \\
\hline 8 & $49, \mathrm{~F}$ & 3 & none & $5-8$ & Neurontin, Lamictal, DHE, NSAIDs & impaired \\
\hline 9 & $43, F$ & 1 & visual aura, numbness & $3-10$ & Benadryl, Compazine, DHE, Toradol & limited \\
\hline 10 & $18, F$ & 5 & none & $7-10$ & Sumatriptan, Celexa, droperidol, NSAIDs & incapacitated \\
\hline 11 & $51, \mathrm{~F}$ & 10 & lacrimation & $6-10$ & $\begin{array}{l}\text { verapamil, Topamax, trazodone, Sumatriptan, Zo- } \\
\text { fran, tramadol }\end{array}$ & incapacitated \\
\hline 12 & $32, \mathrm{M}$ & 6 & none & $6-8$ & ketamine, Compazine, DHE, Cymbalta & impaired \\
\hline 13 & $55, \mathrm{~F}$ & 2 & sweating, dizziness, vision changes & 7 & Fioricet, sertraline, DHE, NSAIDs, Vicodin & impaired \\
\hline 14 & $48, F$ & 6 & lacrimation & $6-9$ & Topamax, aspirin & limited \\
\hline
\end{tabular}

* DHE = dihydroergotamine; MS = morphine sulfate; NSAID = nonsteroidal antiinflammatory drug.

$\dagger$ These patients underwent previous occipital nerve stimulator placement. 
S. Hann and A. Sharan

TABLE 2: Headache stimulation response*

\begin{tabular}{|c|c|c|c|c|c|c|c|c|c|}
\hline $\begin{array}{l}\text { Case } \\
\text { No. }\end{array}$ & $\begin{array}{c}\mathrm{FU} \\
(\mathrm{mos})\end{array}$ & Insertion & $\begin{array}{l}\text { Battery } \\
\text { Location }\end{array}$ & $\begin{array}{c}\% \mathrm{HA} \\
\text { Reduction }\end{array}$ & $\begin{array}{c}\text { Neuro } \\
\text { Symptoms }\end{array}$ & $\begin{array}{l}\text { VAS Score } \\
\text { (reduction) }\end{array}$ & $\begin{array}{l}\text { Postop } \\
\text { Function }\end{array}$ & $\begin{array}{l}\text { Reduced } \\
\text { Narcotics? }\end{array}$ & Comment \\
\hline 1 & 60 & bilat & rt abdomen & $>90 \%$ & resolved & $2(-5)$ & normal & yes & \\
\hline 2 & 53 & rt unilat & rt buttock & $<10 \%$ & persistent & $7(0)$ & impaired & NA & $\begin{array}{l}\text { mixed migraine \& facial pain from } \\
\text { MVA; electrode not reaching medial } \\
\text { canthus region }\end{array}$ \\
\hline $3 \dagger$ & 49 & bilat & rt subclavicular & $70-90 \%$ & resolved & $2(-6)$ & normal & NA & $\begin{array}{l}\text { bilat ONS in } 2007 \text { ( } 90 \% \text { decrease); } \\
\text { HA in frontal area started in 2008; } \\
\text { bilat SONS in } 2009\end{array}$ \\
\hline 4 & 43 & rt unilat & rt buttock & $50-80 \%$ & resolved & $5(-4)$ & normal & NA & \\
\hline 5 & 39 & rt unilat & rt subscapular & $>50 \%$ & persistent & $5(-3)$ & limited & no & $\begin{array}{l}\text { new pain } 3 \text { inches above the SONS } \\
\text { lead; diminished response over } \\
\text { time }\end{array}$ \\
\hline $6 \dagger$ & 37 & bilat & It buttock & $>90 \%$ & NA & $1(-6)$ & limited & NA & $\begin{array}{l}\text { bilat ONS in } 2007 \text { ( } 75-80 \% \text { decrease } \\
\text { in pain) but had persistent frontal } \\
\text { pain; bilat SONS in } 2010\end{array}$ \\
\hline $7 \dagger$ & 33 & bilat & It buttock & $98 \%$ & resolved & $1(-7)$ & normal & NA & $\begin{array}{l}\text { bilat ONS in } 2006 \mathrm{w} / 40 \% \text { relief } \mathrm{w} / \\
\text { persistent frontal pain; bilat SONS } \\
\text { in } 2011\end{array}$ \\
\hline 8 & 29 & rt unilat & rt buttock & $90-100 \%$ & NA & $1(-6)$ & normal & NA & \\
\hline 9 & 25 & rt unilat & rt buttock & $50 \%$ & persists & $2(-5)$ & impaired & NA & \\
\hline 10 & 23 & bilat & It buttock & $<10 \%$ & NA & $7(0)$ & incapacitated & NA & \\
\hline 11 & 22 & rt unilat & rt buttock & $>90 \%$ & resolved & $1(-7)$ & normal & NA & \\
\hline 12 & 10 & It unilat & rt subclavicular & $>60 \%$ & NA & $3(-4)$ & normal & NA & \\
\hline 13 & 6 & It unilat & It buttock & $30 \%$ & persistent & $6(-1)$ & impaired & no & $\begin{array}{l}\text { allodynia from SONS (turned off) but } \\
\text { still gets 30\% relief from ONS }\end{array}$ \\
\hline 14 & 3 & rt unilat & rt subclavicular & $<50 \%$ & persistent & $5(-3)$ & impaired & NA & still in process of reprogramming \\
\hline
\end{tabular}

* FU = follow-up; HA = headache; MVA = motor vehicle accident; NA = not applicable; Neuro = Neurological..

$\dagger$ These patients underwent previous occipital nerve stimulator placement.

for frontal migraine coverage all had excellent responses (70\%-90\%, > 90\%, and 98\% reduction) compared with the initial level of headaches. One of these patients had greater than $90 \%$ reduction with ONS alone but after 1 year started to experience new frontal headache; the other 2 had $75 \%$ and $40 \%$ response to ONS but always had persistent frontal headaches (Table 2). Three patients with regular preoperative narcotic use had poorer response to stimulation $(>90 \%, 50 \%$, and $30 \%$ ) and only 1 was able to stop taking narcotics after the stimulator placement.

Among the 4 nonresponders, 1 patient (Case 2) developed $\mathrm{CM}$ after suffering facial lacerations that had to be surgically repaired following a motor vehicle accident. Her chronic headache had mixed features of migraine and craniofacial pain. After the implantation, she continued to have pain in the medial canthus area, which was not covered by the electrode-induced paresthesia. Because of her overall response rate of less than $10 \%$, a decision was made against placing a supratrochlear lead to cover the medial canthus pain. One patient (Case 10) reported allodynia from electrodes that caused her to be more hypersensitive to pain, and she had a sensation of lead wires tugging on position changes that bothered her (she was a very thin young woman), ultimately leading to removal. Another patient (Case 13) had some response to
ONS but had allodynia at the supraorbital site. Because of this, only the occipital nerve electrodes were used; the supraorbital ones were turned off. The final patient (Case 14) underwent implantation very recently and is still in the process of reprogramming (Table 2).

\section{Adverse Events}

Major complications of the surgery included lead migration (42.8\%), lead site allodynia (21.4\%), and infection due to hardware exposure (14.2\%). Five patients $(35.7 \%)$ required 1 or more reoperations due to infection, incomplete coverage from stimulation, or near electrode exposure. Three patients $(21.4 \%)$ who had very little or no response to stimulation eventually developed electrode site pain or discomfort from the stimulation and elected to have the system removed. All cases of lead malfunction-induced reoperations or removal were related to the SONS electrodes: 6 patients had lead migrations as documented by skull radiography, of whom 2 had lead exposure requiring a course of antibiotic treatment after system removal, and 2 others had near-exposure of an electrode due to thinning of the skin overlying it. Despite this, only 1 patient reported reduction of coverage area from the lead migration. Nearly all battery-related complications such as site infections and tugging discomfort 
happened in batteries in the buttocks, except for 1 patient who worked as a mover and had to have the subclavicular battery moved to the subscapular area because of rubbing against the chest incision while carrying boxes.

In an attempt to reduce the occurrence of lead migration, the senior author started utilizing techniques such as creating 2 loops in lead wires as a tension reliever at the temporal incision site, burying the tip of a stimulator subperiosteally to hold down the lead, and using a titanium dog bone-shaped plate at the base of the SONS lead to stabilize it to the skull. Among the 9 patients without the anchoring titanium plate, lead migration happened in 5 patients $(55.6 \%)$, necessitating corrective surgeries in 4 . On the other hand, among the 5 patients and 2 of the 4 patients who were implanted with an anchoring plate at reoperation, only 1 had lead migration (14.3\%). Paying attention to placing the midpoint of the lead over the target nerve can prevent loss of therapeutic benefit after electrode migration (Table 3 ).

\section{Discussion}

A majority of patients reported marked improvement in headache severity and frequency (71\%), resolution of associated neurological symptoms (50\%), and resumption of a normal functional lifestyle $(50 \%)$. Furthermore, 3 patients with migraine headache initially treated with ONS with varying success had SONS placement at later dates, enabling them all to achieve greater than $90 \%$ of decreased severity. This suggests that adding SONS to ONS may provide better efficacy than ONS alone for CM. Most notable in the current study is perhaps that it offers one of the longest follow-up periods for peripheral nerve stimulation in CM therapy. Of the 9 patients who had longer than 24 months of follow-up (ranging from 25 to 60 months), $8(89 \%)$ had sustained benefit of at least $50 \%$ pain relief from the stimulators based on the most recent follow-up. In keeping with other reported case se- ries, problems included a high rate of electrode migrations, wound infections, and hardware-induced discomfort, necessitating several reoperations. ${ }^{14,17,18,20}$

It has been well established that ONS has excellent efficacy for the treatment of occipital neuralgia or occipitally localized pain with an average of $88 \%$ of individuals attaining greater than $50 \%$ pain relief.,11,16,23 However, when ONS is used to treat primary headache such as cluster headache and CM, the effect has been less than ideal, with a total of $54 \%$ patients with cluster headaches and $47 \%$ with migraine headaches responding to the treatment, according to the comprehensive reviews of neurostimulation for primary headache disorders by Jenkins and Tepper. Table 4 summarizes the current literature of ONS in CM treatment. With the addition of the largest randomized controlled trial by Silberstein et al. ${ }^{20}$ in 2012 , the overall $\mathrm{CM}$ response rate ( $\geq 50 \%$ pain relief) of ONS was found to be $35.7 \%$. A theory behind the superior results of ONS for occipital pain but the subpar effect for CM is rather intuitive. Reed et al. suggested that the location of paresthesia in relation to the pain is the central issue in predicting successful neuromodulation. ${ }^{15}$ Treating occipital pain with ONS-induced paresthesia directly over the occipital nerve is consistent with the traditional approach of neuromodulation involving spinal cord stimulator for the extremities and back pain. Throughout this "traditional" period the clinical approach has always been to produce a paresthesia over the parts of the body that hurt, which indicated that the correct portion of the nervous system was being stimulated.,15 Migraine is more commonly experienced in the frontotemporal area innervated by the trigeminal nerve rather than in the occipitocervical area innervated by the greater occipital nerve; thus, for the neurostimulator to work, the paresthesia induced needs to cover the affected area. ${ }^{15}$ With ONS alone, most of the migraine-affected area of pain is insufficiently covered. The recent evolution of treating the diagnosis of migraine with ONS is a paradigm shift

TABLE 3: Complications, reoperations, and removals

\begin{tabular}{|c|c|c|c|c|c|c|}
\hline $\begin{array}{l}\text { Case } \\
\text { No. }\end{array}$ & Complication & $\begin{array}{c}\text { Lead } \\
\text { Migration? }\end{array}$ & $\begin{array}{c}\text { Plate } \\
\text { Anchor? }\end{array}$ & Battery Location & Reop & Removal \\
\hline 1 & hardware exposure required reinsertion after antibiotics & yes & no & rt abdomen & yes & no \\
\hline 2 & none & no & no & rt buttock & no & no \\
\hline $3^{*}$ & none & no & no & rt subclavicular & no & no \\
\hline 4 & exposed SONS lead required replacement after antibiotics & yes & no & rt buttock & yes & no \\
\hline 5 & none & no & no & rt subscapular & no & no \\
\hline $6^{*}$ & It brow \& rt temporal near exposure required replacement & yes & no & It buttock & yes & no \\
\hline $7^{*}$ & pain over lead, replaced & yes & no & It buttock & yes & no \\
\hline 8 & decreased area of stimulation at most recent follow-up & yes & no & rt buttock & no & no \\
\hline 9 & lead site pain \& not enough relief required removal & no & no & rt buttock & no & yes \\
\hline 10 & no good relief, pain from lead wire pulling required removal & no & yes & It buttock & no & yes \\
\hline 11 & none & no & yes & rt buttock & no & no \\
\hline 12 & poor coverage requiring another ONS placement & no & yes & rt subclavicular & yes & no \\
\hline 13 & removal of SONS due to thinning of skin above SONS causing pain & yes & yes & It buttock & no & yes \\
\hline 14 & none & no & yes & rt subclavicular & no & no \\
\hline
\end{tabular}

* These patients underwent previous occipital nerve stimulator placement. 
that failed to deliver clinical results. Our dual ONS and SONS therapy for CM is returning to the traditional approach of "concordant paresthesia" because it offers better topographical coverage for migraine headache often experienced holohemispherically.

To date, there has been only 1 other report of combined ONS and SONS for CM. In 2010, Reed et al., ${ }^{15}$ a physiatry group in Dallas, Texas, published their successful open-label, nonrandomized trial of combined ONS and SONS therapy for CM. These authors described a case series of 7 patients with CM responding to occipital and supraorbital stimulation. Eight patients were initially evaluated with trial stimulation and only 7 responded. These 7 responders had the choice of using either ONS alone or ONS and SONS combined stimulation during the trial, and all preferred combined therapy. After permanent installation, all 7 patients had greater than 50\% decreased severity with an average pain reduction of $83 \%$. The adverse effect was lead migration in $14 \% .^{15}$ The authors then inferred that to treat head pain, the presence or absence of a diagnosis may be less important than the anatomical concordance in distribution of the pain and induced paresthesia. Our results further strengthen this particular theory (Table 5). We therefore suggest that patients with $\mathrm{CM}$ who do not respond or partially respond to ONS may benefit from additional leads (that is, SONS).

Matharu et al..$^{10}$ used PET studies to further detect the effect of neuromodulation in the brainstem and higher structures in the CNS. In 8 patients with CM undergoing ONS, the neural activity was measured using regional cerebral blood flow detected on a PET scan. When the stimulator was off, the patients with migraines had increased activity in the rostral pons, which is considered to play a key role in CM pathogenesis. As the stimulator is turned on, paresthesia-correlated activation was observed in the cuneus, pulvinar, and anterior cingulate cortex, suggesting that these structures may be important in pain modulation induced by the peripheral nerve stimulation. ${ }^{10}$ All 8 patients had good to excellent pain control from ONS. Most recently, Kovacs et al. ${ }^{9}$ described thalamic activation captured on functional MRI from trial occipital electrodes placed in a healthy volunteer after a safety testing. These discoveries of neurostimulator-induced CNS activation provide another theory for why certain patients with CM have positive response to ONS alone. Future investigations of dual ONS and SONS effects to the CNS with new diagnostic/imaging modality are worthwhile.

In considering the technical aspects of surgery, we realize that high percentages of reoperation and removal are largely due to lead migrations and discomfort at supraorbital nerve stimulator electrodes. This could be due to a wider range of motion in the muscles of facial expression compared with occipital musculature as well as to the facial skin, which is thin and more prone to rubbing than occipital skin. Most of these patients were treated sufficiently through reoperation with the placement of an anchoring titanium plate as described previously. However, 1 patient in whom the supraorbital electrode tip was near the erosion just above the eyebrow required plastic surgery to bury the leads subperiosteally through an eyebrow incision. This patient went on to have continued

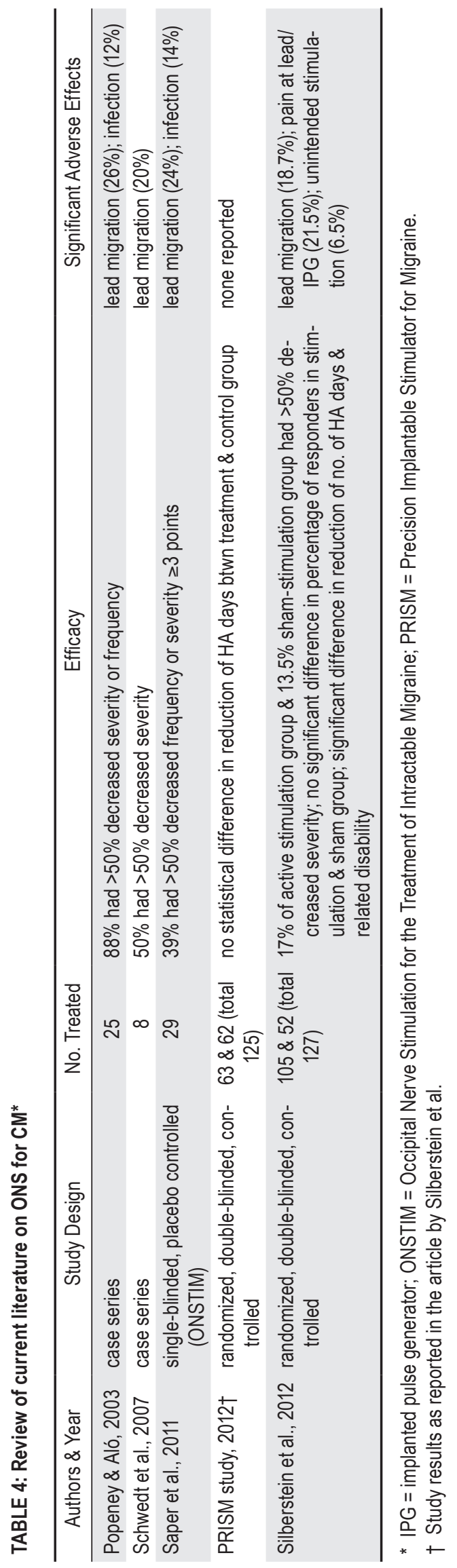

Neurosurg Focus / Volume 35 / September 2013 


\section{Dual occipital and supraorbital nerve stimulation}

TABLE 5: Review of ONS and SONS studies

\begin{tabular}{|c|c|c|c|c|}
\hline Authors \& Year & Study Design & $\begin{array}{c}\text { No. } \\
\text { Treated }\end{array}$ & Efficacy & Significant Adverse Events \\
\hline Reed et al., 2010 & $\begin{array}{l}\text { open-label, non- } \\
\text { blinded trial }\end{array}$ & 7 & $\begin{array}{l}100 \% \text { had }>50 \% \text { decreased } \\
\text { severity }\end{array}$ & lead migration (14\%) \\
\hline current study & case series & 14 & $\begin{array}{l}71 \% \text { had } \geq 50 \% \text { decreased } \\
\quad \text { severity }\end{array}$ & $\begin{array}{l}\text { lead migration (42.8\%), lead allodynia (21.4\%), } \\
\text { infection (14.2\%) }\end{array}$ \\
\hline
\end{tabular}

benefit after the revision. Perhaps as neurosurgeons we ought to develop a more durable way to insert supraorbital leads. One possibility might be to insert supraorbital leads under the pericranium or even periosteum after doing a standard bicoronal skin incision. This would allow anchoring of a lead to the skull directly, thereby reducing motion, and it would also provide thicker skin above a lead and offers more protection from erosion at the forehead. The methods of implantation and anchoring differ among surgeons. Finesse in technique evolves over time with a surgeon's experience. Falowski et al. reported that adding a second strain relief loop reduced occipital nerve lead migration from $62.5 \%$ to $10 \% .^{5}$ A midline incision also allows for less migration than a lateral incision by providing space that allows the leads to be tucked up to the thick fascial band in the median raphe. ${ }^{5}$ With respect to the battery units, we found the subclavicular location to have fewer incidences of dehiscence, infection, and discomfort from pulling compared with the buttocks location. With today's availability of small battery packs, even in thin, young female patients, the subclavicular location should be of no significant cosmetic concern.

\section{Conclusions}

The results of our study indicate that in patients with CM, dual ONS and SONS therapy could offer more frequent pain relief, resolution of associated neurological symptoms, and return of functional capacity compared with ONS alone. These results are also sustained during long-term follow-up. Our case series is limited because it is a single-institution retrospective study with a small sample size and no control group. Further studies involving multicenter randomized controlled trials for combined ONS and SONS therapy are warranted to add a higher level of evidence for this practice. In addition, as neurosurgeons, we are obligated to investigate better surgical techniques to reduce patient morbidity in our endeavor to advance neuromodulation for patient care.

\section{Disclosure}

The authors report no conflict of interest concerning the materials or methods used in this study or the findings specified in this paper.

Author contributions to the study and manuscript preparation include the following. Conception and design: Hann. Acquisition of data: Hann. Analysis and interpretation of data: Hann. Drafting the article: Hann. Critically revising the article: both authors. Reviewed submitted version of manuscript: both authors. Study supervision: Sharan.

\section{References}

1. Amin S, Buvanendran A, Park KS, Kroin JS, Moric M: Peripheral nerve stimulator for the treatment of supraorbital neuralgia: a retrospective case series. Cephalalgia 28:355-359, 2008

2. Bigal ME, Serrano D, Reed M, Lipton RB: Chronic migraine in the population: burden, diagnosis, and satisfaction with treatment. Neurology 71:559-566, 2008

3. Breslau N, Davis GC, Andreski P: Migraine, psychiatric disorders, and suicide attempts: an epidemiologic study of young adults. Psychiatry Res 37:11-23, 1991

4. Burns B, Watkins L, Goadsby PJ: Treatment of hemicrania continua by occipital nerve stimulation with a bion device: longterm follow-up of a crossover study. Lancet Neurol 7:10011012,2008

5. Falowski S, Wang D, Sabesan A, Sharan A: Occipital nerve stimulator systems: review of complications and surgical techniques. Neuromodulation 13:121-125, 2010

6. Headache Classification Subcommittee of the International Headache Society: The International Classification of Headache Disorders: 2nd edition. Cephalgia 24 Suppl 1:9-160, 2004

7. Jenkins B, Tepper SJ: Neurostimulation for primary headache disorders, part 1: pathophysiology and anatomy, history of neuromodulation in headache treatment, and review of peripheral neuromodulation in primary headaches. Headache 51: 1254-1266, 2011

8. Johnson MD, Burchiel KJ: Peripheral stimulation for treatment of trigeminal postherpetic neuralgia and trigeminal posttraumatic neuropathic pain: a pilot study. Neurosurgery 55: 135-142, 2004

9. Kovacs S, Peeters R, De Ridder D, Plazier M, Menovsky T, Sunaert S: Central effects of occipital nerve electrical stimulation studied by functional magnetic resonance imaging. Neuromodulation 14:46-57, 2011

10. Matharu MS, Bartsch T, Ward N, Frackowiak RSJ, Weiner R, Goadsby PJ: Central neuromodulation in chronic migraine patients with suboccipital stimulators: a PET study. Brain 127:220-230, 2004

11. Melvin EA Jr, Jordan FR, Weiner RL, Primm D: Using peripheral stimulation to reduce the pain of C2-mediated occipital headaches: a preliminary report. Pain Physician 10:453-460, 2007

12. Poggi JT, Grizzell BE, Helmer SD: Confirmation of surgical decompression to relieve migraine headaches. Plast Reconstr Surg 122:115-124, 2008

13. Pompili M, Di Cosimo D, Innamorati M, Lester D, Tatarelli R, Martelletti P: Psychiatric comorbidity in patients with chronic daily headache and migraine: a selective overview including personality traits and suicide risk. J Headache Pain 10:283290, 2009

14. Popeney CA, Aló KM: Peripheral neurostimulation for the treatment of chronic, disabling transformed migraine. Headache 43:369-375, 2003

15. Reed KL, Black SB, Banta CJ II, Will KR: Combined occipital and supraorbital neurostimulation for the treatment of 


\section{S. Hann and A. Sharan}

chronic migraine headaches: initial experience. Cephalalgia 30:260-271, 2010

16. Rodrigo-Royo MD, Azcona JM, Quero J, Lorente MC, Acín P, Azcona J: Peripheral neurostimulation in the management of cervicogenic headache: four case reports. Neuromodulation 8:241-248, 2005

17. Saper JR, Dodick DW, Silberstein SD, McCarville S, Sun M, Goadsby PJ: Occipital nerve stimulation for the treatment of intractable chronic migraine headache: ONSTIM feasibility study. Cephalalgia 31:271-285, 2011

18. Schwedt TJ, Dodick DW, Hentz J, Trentman TL, Zimmerman RS: Occipital nerve stimulation for chronic headache-longterm safety and efficacy. Cephalalgia 27:153-157, 2007

19. Schwedt TJ, Dodick DW, Trentman TL, Zimmerman RS: Occipital nerve stimulation for chronic cluster headache and hemicrania continua: pain relief and persistence of autonomic features. Cephalalgia 26:1025-1027, 2006

20. Silberstein SD, Dodick DW, Saper J, Huh B, Slavin KV, Sharan A, et al: Safety and efficacy of peripheral nerve stimulation of the occipital nerves for the management of chronic migraine: results from a randomized, multicenter, double-blinded, controlled study. Cephalalgia 32:1165-1179, 2012

21. Slavin KV, Nersesyan H, Wess C: Peripheral neurostimulation for treatment of intractable occipital neuralgia. Neurosurgery 58:112-119, 2006

22. Trentman TL, Slavin KV, Freeman JA, Zimmerman RS: Occipital nerve stimulator placement via a retromastoid to infraclavicular approach: a technical report. Stereotact Funct Neurosurg 88:121-125, 2010

23. Weiner RL, Reed KL: Peripheral neurostimulation for control of intractable occipital neuralgia. Neuromodulation 2:217221, 1999

24. Winner PK, Sadowsky CH, Martinez WC, Zuniga JA, Poulette A: Concurrent onabotulinumtoxinA treatment of cervical dystonia and concomitant migraine. Headache 52:12191225,2012

Manuscript submitted May 15, 2013.

Accepted June 13, 2013.

Please include this information when citing this paper: DOI: 10.3171/2013.6.FOCUS13233.

Address correspondence to: Shannon Hann, M.D., 1000 Walnut St., Apt. 1506, Philadelphia,PA 19107.email: shannon.hann@jeffer sonhospital.org. 